\title{
KEJADIAN DEPRESI PADA WARGA BINAAN PEMASYARAKATAN PEREMPUAN DI LEMBAGA PEMASYARAKATAN
}

\author{
Mei Rianita Elfrida Sinaga*, Megah Andriany, Artika Nurrahima \\ Program Studi Magister Keperawatan, Fakultas Kedokteran, Universitas Diponegoro, J1. Prof. Soedarto, \\ Tembalang, Kec. Tembalang, Kota Semarang, Jawa Tengah, Indonesia 50275 \\ *ns.mei.sinaga@gmail.com
}

\begin{abstract}
ABSTRAK
Meningkatnya jumlah warga binaan pemasyarakatan (WBP) perempuan di lapas menyebabkan munculnya masalah psikologis termasuk depresi. Depresi yang dialami WBP perempuan berdampak pada aspek lain yaitu keluarga, anak, dan komunitas. Kondisi ini menjadi beban tambahan bagi WBP perempuan selama di lapas dikarenakan terpisah dari anak, masalah hak asuh anak, larangan kontak dengan anak, kegagalan peran menjadi ibu maupun istri sehingga memiliki pandangan negatif terhadap diri sendiri, orang lain, dan masa depan, dapat berpengaruh buruk secara berkelanjutan memicu terjadinya perilaku negatif seperti melukai diri sendiri bahkan bunuh diri. Tujuan dari penelitian ini adalah untuk menggambarkan masalah depresi yang dialami WBP perempuan selama menjalani masa pidana di Lapas. Metode penelitian yang digunakan deskriptif kuantitatif. Pengumpulan data dilakukan menggunakan kuesioner Beck Depression Inventory-II (BDI-II). Subjek penelitian sebanyak 159 WBP perempuan yang dipilih menggunakan teknik purposive random sampling dengan kriteria inklusi usia 18 tahun ke atas, sudah mendapatkan putusan vonis menjalani masa pidana dan kriteria eksklusi adalah WBP perempuan yang berada di ruang isolasi, tidak memiliki penyakit kronis, dan residivisme. Hasil penelitian menunjukkan bahwa tingkat depresi WBP perempuan kategori ringan sampai sedang.
\end{abstract}

Kata kunci: depresi, warga binaan pemasyarakatan perempuan

\section{THE INCIDENCE OF DEPRESSION ON FEMALE INMATES IN CORRECTIONAL SETTING}

\begin{abstract}
The increasing number of female inmates in Prison led to the emergence of psychological problems including depression. Depression experienced by female inmate's impact on other aspects, namely family, children, and community. This condition becomes an additional burden for the female inmates in Prison due to separate from the child, the issue of child custody, a ban on contact with children, the failure of the role of being a mother and wife and so have a negative view of themselves, others, and future can be a bad influence in a sustainable trigger the occurrence of negative behaviors such as self-mutilation and even suicide. The purpose of this study is to describe the problem of depression experienced by female inmates during a period of criminal in Prison. The research method used descriptive quantitative. Data collection was done using Beck Depression Inventory-II (BDI-II) questionnaires. The subject of the study a total of 159 female inmates selected using purposive random sampling with the inclusion criteria of age 18 years and above, already get the verdict undergo a criminal past and an exclusion criterion is a female inmate who are in isolation, do not have a chronic illness, and recidivism. The results showed that the level of depression female inmate's category of mild to moderate.
\end{abstract}

Keywords: depression, female inmates

\section{PENDAHULUAN}

Data statistik WHO (World Health Organization) menyebutkan bahwa setiap $1 \%$ dari seluruh penduduk di dunia berada dalam kondisi membutuhkan pertolongan dan pengobatan untuk berbagai bentuk masalah kesehatan mental (Estimates, 2012). Kondisi ini menunjukkan bahwa kesehatan mental merupakan salah satu masalah kesehatan komunitas yang besar dibandingkan dengan masalah kesehatan lainnya yang ada di masyarakat (Hendriyana). Kondisi ini juga terjadi pada warga binaan pemasyarakatan perempuan (WBP), didukung oleh data World Prison Brief bahwa populasi perempuan di lembaga pemasyarakatan (lapas) sejak tahun 
2000 semakin meningkat termasuk Indonesia (Walmsley, 2017). Jumlah WBP perempuan di beberapa wilayah di Indonesia menunjukkan mengalami over kapasitas, salah satunya lapas di Jawa Tengah tahun 2018 mengalami over kapasitas sebesar 98\% (Direktorat jenderal pemasyarakatan, 2018). Meningkatnya jumlah WBP perempuan di lapas mempengaruhi terjadinya gangguan mental, masalah kecanduan, gangguan bipolar lima kali lebih besar termasuk depresi (Blitz, Wolff, Pan, \& Pogorzelski, 2005).

Sama halnya dengan Indonesia sejak tahun 2013 sampai Februari 2018 mencapai 91.69\% (BPS, 2017; Direktorat Jendral Pemasyarakatan, 2019). Kondisi ini erat kaitannya dapat memicu ketegangan dan kekerasan, memperparah kesehatan fisik dan mental dan meningkatkan risiko penularan penyakit menular (Direktorat jenderal pemasyarakatan, 2018). Depresi pada WBP perempuan disebabkan karena perlu penyesuaian dengan lingkungan baru di lapas (Pettus-davis, Veeh, Davis, \& Tripodi, 2017), kondisi over kapasitas menyebabkan minimnya sarana kesehatan dan munculnya masalah psikologis (Gunter, 2004). Sumbersumber depresi pada WBP perempuan lebih banyak dibanding laki-laki seperti masalah sosial ekonomi, urusan keluarga, kurangnya kesempatan pendidikan, masalah pernikahan bahkan lebih meningkat apabila sudah memiliki anak (Ahmad \& Mazlan, 2014; Gunter, 2004; Pierre, 2016). Kondisi ini menjadi beban tambahan bagi WBP perempuan selama di lapas, terpisah dari anak, masalah hak asuh anak, larangan kontak dengan anak, kegagalan peran menjadi ibu sehingga memiliki pandangan negatif terhadap diri sendiri, dunia, dan masa depan (Beck, 2013).

Hal ini menunjukkan bahwa perempuan termasuk dalam kelompok vulnerable dan kondisi yang dialaminya akan berdampak pada aspek lain yaitu keluarga, anak, dan komunitas (Covington, 2003). Secara psikologis, perempuan bertindak lebih menggunakan perasaan, sehingga bila mengahadapi suatu maslaah mudah utnuk menyalahkan diri sendiri dan menyebabkan trauma, dan lebih cenderung mengalami episode gangguan mood (Baier, Fritsch, Ignatyev, Priebe, \& Mundt, 2016; Gussak, 2009; Kamoyo, Barchok, Mburugu, \& Nyaga, 2015; Tung, Hsiao, Shen, \& Huang, 2018).
Permasalahan depresi yang dialami WBP perempuan erat kaitannya dengan pengalaman menjalani pemenjaraan (Kamoyo et al., 2015). Pengalaman pemenjaraan berisiko dua kali menyebabkan terjadinya depresi dikarenakan trauma yang pernah dialami (Baier et al., 2016; Shrestha et al., 2017), sehingga mengalami kesulitas untuk memprediksi masa depan (Johnson \& Zlotnick, 2012). WBP perempuan menjadi depresi ketika menentukan atribusi bahwa tidak memiliki kontrol terhadap stres yang terjadi dalam kehidupannya (Palmer \& Connelly, 2005; Pennington, Cramer, Miller, \& Anastasi, 2015).

WBP perempuan di Lapas mengalami perubahan secara fisik, psikologis dan sosial (Fazel \& Danesh, 2002; Gulo, 2013; Hilman \& Indrawati, 2017; Lord, 2008). Secara fisik, WBP perempuan mengalami keterbatasan terhadap lingkungan luar (kehilangan sinar matahari, ruangan yang over kapasitas), tidur dengan orang yang baru dikenal, di lantai dengan bau yang tidak enak, makanan yang rendah nutrisi, gaya hidup yang monoton dan berada dengan orang-orang keras dan agresif (Constantino, Assis, \& Pinto, 2016); secara psikologis, WBP perempuan mengalami perubahan pubertas yang dapat mengakibatkan rendahnya tingkat karakteristik instrumental dan mempengaruhi harga diri dan body images, dan kejadian trauma (Blitz et al., 2005; Marcotte, Fortin, Potvin, \& Papillon, 2002); sedangkan secara sosial, WBP perempuan akan mengalami terbatasnya waktu kunjungan dengan keluarga, berpisah dari anak dan keluarga, kurangnya privasi (Andriany, 2008; Beyen, Dadi, Dachew, Muluneh, \& Bisetegn, 2017; Fazel, Hayes, Bartellas, Clerici, \& Trestman, 2016).

Depresi pada WBP perempuan berdampak pada gangguan psikologis, dapat memicu terjadinya perilaku negatif seperti melukai diri sendiri bahkan bunuh diri pada tahun-tahun awal berada di lapas (Ahmad \& Mazlan, 2014; Kamoyo et al., 2015; Majekodunmi, Obadeji, Oluwole, \& Oyelami, 2017). Selain itu, depresi dapat menyebabkan perubahan mood yang mempengaruhi pada kondisi fsik dan somatis seperti gangguan pola tidur, kelelahan, dan penurunan konsentrasi (Cabeldue, Blackburn, \& Mullings, 2018), meningkatnya kematian karena penyalahgunaan obat-obatan (Shrestha et al., 2017), gangguan mental, kekerasan seksual, dan terjadinya penyakit kronis yang 
kompleks seperti hipertensi, asma, diabetes, penyakit jantung, dan penyakit menular seksual (Chen, Lai, \& Lin, 2014).

Depresi menjadi kontributor kedua beban penyakit global pada tahun 2020 (WHO, 2001). Hal ini didukung dengan pendapat Fazel bahwa WBP perempuan di Lapas mengalami masalah sangat kompleks, empat persen gangguan psikotik, dua belas persen depresi mayor, dua puluh satu persen gangguan kepribadian, dan empat puluh dua persen gangguan antisocial (Fazel \& Danesh, 2002), dan lebih difokuskan pada pengobatan medis setelah depresi yang dialami tingkat berat (Bland \& Streiner, 2013). Kondisi tersebut membuat peneliti tertarik melakukan penelitian menggunakan studi deskriptif dengan tujuan untuk menggambarkan masalah depresi yang dialami WBP perempuan selama menjalani masa pidana di Lapas Perempuan Kelas IIA Semarang.

\section{METODE}

Metode penelitian yang digunakan dalam penelitian adalah deskriptif kuantitatif. Pengumpulan data dilakukan menggunakan kuesioner Beck Depression Inventory-II (BDIII) yang terdiri dari 21 item pertanyaan untuk mengukur tingkat depresi WBP perempuan. Kuesioner BDI-II diadopsi dari penelitian Jodi, dengan $r_{\text {tabel }}=0,36$ dan nilai alpha $(\alpha)=0,88$, artinya bahwa kuesioner tersebut sudah valid dan reliabel (Jodi, 2016). Rata-rata waktu yang diperlukan responden untuk melengkapi isian kuesioner 10 menit. Analisa data dalam penelitian ini menggunakan analisa univariat berupa distribusi frekuensi yang kemudian disajikan dalam bentuk persentase. Sebelum dilakukan pengumpulan data, peneliti menjelaskan tujuan dan prosedur penelitian serta meminta persetujuan dengan menandatangani informed consent.

Peneliti mendampingi responden saat mengisi kuesioner sehingga dapat dipastikan tidak ada item pertanyaan yang tidak lengkap. Responden dalam penelitian sebanyak 159 WBP perempuan dari total populasi sejumlah 300 WBP perempuan yang dipilih menggunakan teknik purposive random sampling dengan kriteria inklusi usia 18 tahun ke atas, sudah mendapatkan putusan vonis menjalani masa pidana dan kriteria eksklusi adalah WBP perempuan yang berada di ruang isolasi, tidak memiliki penyakit kronis, dan residivisme. Penelitian ini dilakukan di Lapas Perempuan Kelas IIA Semarang pada bulan September 2019. Penelitian dilakukan setelah mendapat persetujuan dari Komisi Etik Penelitian Departemen Ilmu Keperawatan Fakultas Kedokteran Universitas Diponegoro dengan Nomor 41/EC/KEPK/D.Kep/VI/2019.

\section{HASIL}

Lapas Perempuan Kelas II memiliki fasilitas Poliklinik kesehatan dengan petugas kesehatan berjumlah 2 perawat dan 1 dokter untuk memberikan pelayanan kesehatan bagi WBP perempuan. Pelayanan kesehatan yang diberikan masih lebih berfokus pada kesehatan secara fisik dikarenakan kurangnya SDM yang khusus untuk menyelesaikan masalah kesehatan mental. Masalah kesehatan mental sudah dilakukan tetapi belum optimal. Lapas ini memiliki sistem alur rujukan ke beberapa rumah sakit maupun pelayanan kesehatan lainnya yang sudah bekerjasama, sehingga apabila ditemukan kasus yang serius pihak lapas merujuk WBP perempuan tersebut. Upaya promotif dan preventif juga dilakukan pihak lapas dengan melibatkan peran koordinasi dan partnership antar instansi pendidikan maupun departemen lainnya seperti departemen keagamaan dalam hal konseling pendekatan spiritual, pendidikan dalam hal kejar paket A,B,dan C.

Secara keseluruhan, responden dalam penelitian ini berjumlah 159 WBP perempuan. Pengukuran tingkat depresi dilakukan sesuai dengan kategori BDI-II (Sorayah, 2015). Depresi yang dialami WBP perempuan menunjukkan perubahan pada kognitif, afektif, dan somatik (Maunder \& Cameron, 2013). Karakteristik responden berdasarkan usia, tingkat pendidikan, status pernikahan, dan lama pidana dapat dilihat pada Tabel 1 . Gambaran depresi yang dialami WBP perempuan dapat dilihat pada Tabel 2 . 
Tabel 1.

Karakteristik responden $(n=159)$

\begin{tabular}{lcc}
\multicolumn{1}{c}{ Variabel } & $\mathrm{f}$ & $\%$ \\
\hline Usia (tahun) & 50 & 31,4 \\
$18-28$ & 97 & 61 \\
$29-40$ & 12 & 7,5 \\
$>40$ & & \\
Tingkat pendidikan & 53 & 33,3 \\
Rendah (SD, SMP) & 106 & 66,7 \\
Tinggi (SMA, PT) & & \\
Status pernikahan & 127 & 79,9 \\
Menikah & 32 & 20,1 \\
Belum Menikah & & 3,1 \\
Lama pidana (tahun) & 5 & 48,4 \\
$<1$ & 77 & 31,4 \\
1-5 & 50 & 17 \\
6-10 & 27 & \\
$>10$ & & \\
\hline
\end{tabular}

Mayoritas responden berusia 29-40 tahun,

berpendidikan tinggi, menikah, dan lama

pidana 1-5 tahun.

Tabel. 2

Depresi WBP perempuan $(n=159)$

\begin{tabular}{lcc}
\hline \multicolumn{1}{c}{ Tingkat Depresi } & $\mathrm{f}$ & $\%$ \\
\hline Normal & 24 & 15,1 \\
Depresi ringan & 86 & 54,1 \\
Depresi sedang & 39 & 24,5 \\
Depresi berat & 10 & 6,3 \\
\hline
\end{tabular}

\section{PEMBAHASAN}

Tabel 1, usia responden dalam penelitian ini rata-rata 29 sampai 40 tahun $(61 \%)$. Usia erat kaitannya dengan tugas perkembangan. Responden penelitian ini kategori dewasa dengan tugas perkembangan seperti membangun hubungan intim dengan pasangan dan keluarga serta hubungan sosial dalam kelompok (Hurlock, 2009). Hal ini sesuai dengan penelitian (Jodi, 2016; Unver, Yuce, Bayram, \& Bilgel, 2013), tetapi tidak sesuai dengan penelitian Bedaso bahwa depresi dapat diatasi dengan cara WBP perempuan tersebut ikut aktif dalam kegiatan produktif di lapas seperti latihan bimbingan kerja (Bedaso, Kediro, \& Yeneabat, 2018). Dalam menjalankan tugas perkembangan tersebut, WBP perempuan menghadapi konflik yang berkaitan dengan tanggung jawab terhadap diri sendiri dan orang lain. Ketidakmampuan WBP perempuan menyesuaikan diri dan menyelesaikan persoalan hidup menyebabkan terjadinya depresi (Pinese, Furegato, \& Santos, 2010).
Tingkat pendidikan, rata-rata responden memiliki pendidikan minimal SMA/sederajat $(66,7 \%)$. Tingkat pendidikan akan mempengaruhi WBP perempuan tersebut dalam hal merespon masalah yang dihadapi (Unver et al., 2013). Semakin rendah pendidikan, maka terjadinya depresi semakin besar, berkaitan dengan ketidakmampuan merespon masalah dan menemukan solusi. Tingkat pendidikan yang tinggi menunjukkan kemampuan untuk mengembangkan intelektualitas, kreatifitas, dan aktualiasi ilmu pengetahuan dlaam mengahadpi tantangan hidup tetapi tidka menjamin munculnya perilaku yang adaptif (Baier et al., 2016).

Berdasarkan status pernikahan, sebagian besar responden sudah menikah dan memiliki anak $(79,9 \%)$. Hal ini didukung oleh penelitian bahwa WBP perempuan yang sudah menikah bahkan sudah memiliki anak memiliki risiko mengalami tekanan psikologis lebih besar dikarenakan tanggung jawab terhadap pasangan, anak, dan keluarga, peran ibu yang tidak optimal dalam hak asuh (Ahmad \& Mazlan, 2014; Pierre, 2016). Status 
pernikahan dapat memberikan dampak positif bagi WBP perempuan bila hubungan dalam pernikahan dan keluarga harmonis dan adanya komunikasi yang baik, tetapi akan berdampak negatif terhadap kondisi WBP perempuan selama di lapas bila hubungan dalam pernikahan tidak baik bahkan adanya risiko perceraian dan perebutan hak ahli asuh anak.

Berdasarkan lama pidana yang dijalani, ratarata WBP perempuan menjalani masa pidana 1-5 tahun $(48,4 \%)$. Kumar berpendapat bahwa episode stres dan depresi yang paling tinggi muncul ketika menjalani masa persidangan dikarenakan fase awal penyesuaian di lapas dan adanya ketidakpastiasn tentang putusan lama pidana yang akan dijalani (Kumar \& Daria, 2013). Didukung juga dengan hasil penelitian lainnya bahwa semakin lama masa pidana yang dijalani WBP perempuan kaitannya dengan kehilangan pekerjaan atau sumber penghasilan sehingga akan semakin mudah mengalami depresi dan merasa harga diri rendah (Tololiu \& Makalalag, 2015)

Berdasarkan Tabel 2, rata-rata tingkat depresi WBP perempuan di Lapas Perempuan Kelas IIA Semarang kategori ringan sampai sedang. Hal ini dapat disebabkan karena pertama, adanya program pembinaan yang dilakukan pihak lapas seperti kegiatan kerohanian, berfungsi sebagai mekanisme koping bagi WBP perempuan dalam melakukan penyesuaian agar dapat menjalani masa pidana. Hasil penelitian menunjukkan kegiatan keagamaan secara rutin memiliki pengaruh bermakna dalam menurunkan tingkat depresi WBP perempuan (Levitt \& Loper, 2009). Kedua, lapas bukan hanya sebagai tempat pemenjaraan tetapi memberikan bimbingan latihan kerja (Bimker) bagi WBP perempuan seperti membatik, merajut, tata rias, memasak, dsb yang nantinya akan menjadi keahlian dalam membantu mengumpulkan modal saat kembali ke komunitas. Selain itu, interaksi antar sesama merupakan hal penting dalam terjadinya pemulihan, rspon positif melalui kontribusi dan keaktifan individu merupakan suatu keberhasilan (Kennedy, 2010).

Setiap responden menunjukkan perubahan pada domain kognitif, afaektif maupun somatik. Perubahan pada domain kognitif artinya responden mampu berpikir rasional, dapat dilihat dengan respon kepercayaan diri dalam mengambil keputusan, dapat menerima kondisi saat ini dan memperbaiki diri, memiliki pandangan optimis terhadap masa depan, tidak memiliki keinginan untuk bunuh diri. Responden penelitian menemukan motivasi hidup melalui pendekatan diri kepada Allah, keinginan untuk segera bertemu anak dan keluarga. Hal ini sesuai dengan hasil penelitian bahwa kekuatan spiritual dapat memotivasi energi, mengurangi emosi negatif sehingga WBP perempuan tersebut mampu menghadapi tekanan psikologis dengan mengikuti berbagai kegiatan keagamaan dan bimbingan rohani yang ada di Lapas (Nedderman, Underwood, \& Hardy, 2010).

Perubahan pada domain afektif yang dialami WBP perempuan rata-rata adalah gelisah dan kehilangan ketertarikan. Hal ini merupakan respon yang dirasakan akibat penilaian negatif terhadap diri sendiri yang dapat berdampak memiliki pandangan negatif terhadap diri sendiri, orang lain, dan bahkan masa depan. Beberapa responden mampu mengalihkan penilaian negatif ke arah positif dengan aktif mengikuti latihan dan bimbingan kerja, sharing dengan teman-teman di Lapas, lebih mendekatkan diri pada Allah dengan kegiatan kerohanian sesuai jadwal. Hal ini sejalan dengan penelitian yang dilakukan oleh Kennedy menyatakan bahwa interaksi antar sesama merupakan hal penting dalam terjadinya pemulihan. Selain itu, respon positif yang ditunjukkan melalui kontribusi dan keaktifan individu dalam suatu kegiatan merupakan suatu keberhasilan (Kennedy, 2010). Sedangkan pada domain somatik perubahan yang dialami WBP perempuan kebanyakan adalah perubahan pola tidur. Kondisi ini dapat terjadi dipengaruhi kondisi mood karena kesedihan yang dirasakan dapat menyebabkan perubahan pada kerja hipotalamus yang dapat mempengaruhi pola tidur (Semiun, 2006)

\section{SIMPULAN}

Masalah depresi yang dialami WBP perempuan selama menjalani masa pidana di lapas termasuk kategori ringan sampai sedang. Terjadinya depresi dapat dipengaruhi oleh faktor internal maupun eksternal. Faktor-faktor internal tersebut adalah usia, tingkat pendidikan, status pernikahan, dan lama pidana, sedangkan faktor eksternalnya adalah adanya program yang ada di lapas. 


\section{DAFTAR PUSTAKA}

Ahmad, A., \& Mazlan, N. H. (2014). Stress and depression: a comparison study between men and women inmates in Peninsular Malaysia. International Journal of Humanities and Social Science, 4(2), 153-160.

Andriany, M. (2008). Pengalaman narapidana wanita dalam menghadapi masa kebebasan di Lapas wanita kelas IIA Semarang.

Baier, A., Fritsch, R., Ignatyev, Y., Priebe, S., \& Mundt, A. P. (2016). The course of major depression during imprisonment A one year cohort study. Journal of Affective Disorders, 189, 207-213. https://doi.org/10.1016/j.jad.2015.09.00 3

Bedaso, A., Kediro, G., \& Yeneabat, T. (2018). Factors associated with depression among prisoners in Southern Ethiopia : a cross-sectional study. $B M C$ Research Notes, 11(1), 1-6. https://doi.org/10.1186/s13104-0183745-3

Beyen, T. K., Dadi, A. F., Dachew, B. A., Muluneh, N. Y., \& Bisetegn, T. A. (2017). More than eight in every nineteen inmates were living with depression at Prisons of Northwest Amhara Regional State, Ethiopia: a cross sectional study design. $B M C$ Psychiatry, 17(1), 1-9. https://doi.org/10.1186/s12888-0161179-9

Bland, R. C., \& Streiner, D. L. (2013). Recommendations on screening for depression in adults. Canadian Medical Association Journal, 185(9), 753-754. https://doi.org/10.1503/cmaj.130634

Blitz, C. L., Wolff, N., Pan, K., \& Pogorzelski, W. (2005). Gender-specific behavioral health and community release patterns among new jersey prison inmates: implications for treatment and community reentry. American Journal of Public Health, 95(10), 1741-1746. https://doi.org/10.2105/AJPH.2004.059 733
BPS. Statistik Kriminal (2017). Retrieved from bps.go.id

Cabeldue, M., Blackburn, A., \& Mullings, J. L. (2018). Mental health among incarcerated women : an examination of factors impacting depression and PTSD symptomology. Women \& Criminal Justice, $1-$ 21.https://doi.org/10.1080/08974454.20 18.1433099

Chen, Y., Lai, Y., \& Lin, C. (2014). The Impact of prison adjustment among women offenders: a taiwanese perspective. The Prison Journal, 94(1), 7-29.

https://doi.org/10.1177/0032885513512 083

Constantino, P., Assis, S. G. de, \& Pinto, L. W. (2016). The impact of prisons on the mental health of prisoners in the state of Rio de Janeiro, Brazil. Ciência \& Saúde Coletiva, 21(7), 20892100.https://doi.org/10.1590/141381232015217.01222016

Covington, S. S. (2003). A woman's journey home: challenges for female offenders. (Jeremy Travis and Michelle Waul, Ed.), Prisoners once removed: the impact of incarceration and reentry on children, families, and communities. Washington DC: Urban Institute.

Direktorat jenderal pemasyarakatan. (2018). Laporan UPT. Retrieved from http://smslap.ditjenpas.go.id

Direktorat Jendral Pemasyarakatan. (2019). Sistem database pemasyarakatan: Data terakhir jumlah penghuni perkanwil.

Estimates, G. H. (2012). Geneva: World Health Organization. Available from: Http://Www. Who.Int/Healthinfo/Global _burden_disease/En/ [Cited 2016 June $1]$.

Fazel, S., \& Danesh, J. (2002). Serious mental disorder in 23000 prisoners: a systematic review of 62 surveys. The Lancet, $\quad 359, \quad 545-550$. https://doi.org/10.1016/S0140- 
6736(02)07740-1

Fazel, S., Hayes, A. J., Bartellas, K., Clerici, M., \& Trestman, R. (2016). Mental health of prisoners: prevalence, adverse outcomes, and interventions. The Lancet Psychiatry, 3(9), 871881.https://doi.org/10.1016/S22150366(16)30142-0

Gulo, K. J. Hubungan antara dukungan sosial keluarga dengan depresi pada narapidana Lapas IIA Wirogunan Yogyakarta (2013).

Gunter. (2004). Incarcerated women and depression : a primer for the primary care provider. Journal of the American Medical Women's Association (1972), 59(2), 107-112. Retrieved from http://www.ncbi.nlm.nih.gov/pubmed

Gussak, D. (2009). Comparing the effectiveness of art therapy on depression and locus of control of male and female inmates. The Arts in Psychotherapy, 36(4), 202-207. https://doi.org/10.1016/j.aip.2009.02.00 4

Hendriyana, A. (n.d.). Setiap Tahun Penderita Gangguan Jiwa di Indonesia Terus Meningkat.

Hilman, D. P., \& Indrawati, E. S. (2017). Pengalaman menjadi narapidana remaja di Lapas Klas I Semarang. Jurrnal Empati, 7(Nomor 3), 189-203.

Hurlock, E. B. (2009). Psikologi perkembangan: suatu pendekatan sepanjang rentang kehidupan. Jakarta: Erlangga.

Jodi, T. R. (2016). Gambaran tingkat depresi narapidana di lembaga pemasyarakatan wanita kelas IIA Bulu Semarang. Skripsi.

Johnson, J. E., \& Zlotnick, C. (2012). Pilot study of treatment for major depression among women prisoners with substance use disorder. Journal of Psychiatric Research, 46(9), 1174-1183. https://doi.org/10.1016/j.jpsychires.2012
.05 .007

Kamoyo, J. M., Barchok, H. K., Mburugu, B. M., \& Nyaga, V. K. (2015). Effects of imprisonment on depression among female inmates in selected prison in Kenya. Research on Humanities and Social Sciences, 5(16), 55-60. Retrieved from www.iiste.org

Kennedy. (2010). Personal counseling theory: hope therapy. (Liberty University, Ed.).

Kumar, V., \& Daria, U. (2013). Psychiatric morbidity in prisoners. Indian Journal of Psychiatry, 55(4), 366-370. https://doi.org/10.4103/00195545.120562

Levitt, L., \& Loper, A. B. (2009). The influence of religious participation on the adjustment of female inmates. American Journal of Orthopsychiatry, $79(1)$, $1-7$. https://doi.org/10.1037/a001549

Lord, E. A. (2008). The challenges of mentally ill female offenders in prison. Criminal Justice and Behavior, 35(8), 928-942. https://doi.org/10.1177/0093854808318 660

Majekodunmi, O. E., Obadeji, A., Oluwole, L. O., \& Oyelami, R. O. (2017). Depression in prison population: demographic and clinical predictors. Journal of Forensic Science and Medicine,

3237.https://doi.org/10.4103/jfsm.jfsm

Marcotte, D., Fortin, L., Potvin, P., \& Papillon, M. (2002). Gender differences in depressive symptoms during adolescence: role of gender-typed characteristics, self-esteem, body images, stressful life events, and pubertal status. Journal of Emotional and Behavioral Disorders. https://doi.org/10.1177/1063426602010 00104

Maunder, L., \& Cameron, L. (2013). Depression and low mood for people in prison: a self help guide (pp. 1-28). NHS Foundation Trust. Retrieved from 
www.penninecare.nhs.uk

Nedderman, A. B., Underwood, L. A., \& Hardy, V. L. (2010). Spirituality group with female prisoners : impacting hope. Journal of Correctional Health Care, 16(2), 117-132. https://doi.org/10.1177/1078345809356 526

Palmer, E. J., \& Connelly, R. (2005). Depression, hopelessness and suicide ideation among vulnerable prisoners. Criminal Behaviour and Mental Health, 15(3), 164-170. https://doi.org/10.1002/cbm.4

Pennington, C. R., Cramer, R. J., Miller, H. A., \& Anastasi, J. S. (2015). Psychopathy, depression, and anxiety as predictors of suicidal ideation in offenders. Death Studies, 39(5), 288295.https://doi.org/10.1080/0748118 7.2014.991953

Pettus-davis, C., Veeh, C. A., Davis, M., \& Tripodi, S. (2017). Gender differences in experiences of social support among men and women releasing from prison. Journal of Social and Personal Relationships, 1-22. https://doi.org/10.1177/0265407517705 492

Pierre, E. (2016). Mental health rights of incarcerated mothers who are accompanied by their children in a Kenyan Prison.

Pinese, C. S., Furegato, A. R., \& Santos, J. L. (2010). Demographic and clinical predictors of depressive symptoms among incarcerated women. Annals of General Psychiatry, 9, 1-7. Retrieved from http://www.annals-generalpsychiatry.com
Semiun. (2006). Kesehatan mental. Yogyakarta: Kanisius.

Shrestha, G., Yadav, D. K., Sapkota, N., Baral, D., Yadav, B. K., Chakravartty, A., \& Pokharel, P. K. (2017). Depression among inmates in a regional prison of Eastern Nepal: a cross-sectional study. BMC Psychiatry, 17(1), 19.https://doi.org/10.1186/s12888-0171514-9

Sorayah. (2015). Uji validitas konstruk Beck Depression Inventory-II (BDI-II). Jurnal Pengukuran Psikologi Dan Pendidikan Indonesia, IV(1).

Tololiu, T. A., \& Makalalag, H. (2015). Hubungan depresi dengan lama masa tahanan narapidana di rumah tahanan negara kelas IIA Malendeng Manado. Juiperdo, 4(1), 14-19.

Tung, T. H., Hsiao, Y. Y., Shen, S. A., \& Huang, C. (2018). The prevalence of mental disorders in Taiwanese prisons : a nationwide population-based study. Social Psychiatry and Psychiatric Epidemiology.

https://doi.org/10.1007/s00127-0181614-y

Unver, Y., Yuce, M., Bayram, N., \& Bilgel, N. (2013). Prevalence of depression, anxiety, stress, and anger in Turkish Prisoners. Journal of Forensic Sciences, 58(5), 1210-1218. https://doi.org/10.1111/15564029.12142

Walmsley, R. (2017). World female Imprisonment List (fourth edition). London, United Kingdom.

WHO. (2001). Mental health: new understanding, new hope. 